\title{
COMPLEX WORKS PROJECT MANAGEMENT ENHANCED BY DIGITAL TECHNOLOGIES
}

\author{
FRANCESCO RUPERTO $^{1} \&$ STEFANIA STRAPPINI ${ }^{2}$ \\ ${ }^{1}$ Department of Planning, Design and Technology of Architecture (PDTA), University of Rome La Sapienza, Italy \\ ${ }^{2}$ ENEL Task Force, Italy
}

\begin{abstract}
The digital transformation of the construction sector is aimed at increasing the levels of effectiveness and efficiency of construction and operating project management, improving, the expected levels of sustainability and favoring risk management with a data-based knowledge. The paper describes, in methodological and operational terms, the main research and development activities of the ENEL HQVRM - Digital Twin that is aimed at project management objectives of ENEL HQVRM Task Force for the new ENEL Head Quarters in Rome Viale Regina Margherita. The paper mainly illustrates the experimentation, conducted by a joint ENEL-CITERA working group, of modalities for platforming the project's organizational model, which allows for the collection, sharing and measurement in streaming of the main parameters and the simultaneous verification of compliance with contractual provisions. The HQVRM (Head Quarters Viale Regina Margherita) - Digital Twin is based on a common data environment (CDE) of the organizational model and from the point of view of technologies is enabled by cloud computing, artificial intelligence, machine learning, big data and building information modeling (BIM). HQVRM-CDE represents the connective of the digital ecosystem in which information models are organized depending on the need and the objectives to be pursued in particular for the temporal, economic, safety and sustainability aspects. From the client's perspective, the research investigates and experiments by implementing a CDE, replicable and scalable Digital Twin, in order to make the potential of ICT technologies available to project stakeholders in managing the complexities of a building for office use high architectural and representative value, with significant structural interventions and high plant integration for a total amount of $€ 150$ million in more than 3 years long works. An intervention that summarizes in itself the meanings of complexity as referable to those works characterized by particular complexity in relation to the type of works, the use of innovative materials and components, the execution in places that present logistical difficulties or particular environmental issues.
\end{abstract}

Keywords. project management, digital twin, BIM, artificial intelligence, cognitive services.

\section{INTRODUCTION}

The digital transformation involves companies in every sector and it defines a perimeter that is still being defined and that comes to involve the actions of people in the work, personal and social sphere. With digital technologies, organizations change, jobs change, individuals change. Innovative technologies disrupt established practices and disciplines, reshaping new ways of operating by forcing a project that also involves organizational models, work and skills integrated with each other. In this context, the management of the transition makes many managers of organizations oscillate between relying completely on technology suppliers or choosing the path of resistance to change in the name of a comfort zone that is reassuring but whose inefficiency is equally well known. This unstable equilibrium is also experienced in the AECO sector and involves large client companies, designers and companies each called their own way of interpreting BIM, an acronym that is too synthetic to represent a multiplicity of meanings.

This paper describes the effort put in place by ENEL S.p.A., Sapienza University of Rome in digitally transforming the operating methods of the construction site of the new Rome headquarters in Viale Regina Margherita. The project called HQVRM CDE is still in progress 
and is aimed at creating complex systems for risk management and for a better quality of the work. A work in progress that involves a complex organizational model that also includes the companies responsible for both the PMO and the construction of the work including the entire supply chain. This research which constitutes a useful opportunity to experiment a methodological approach of a construction site digital twin [1]-[3] implementation, potentially able at the same time to evaluate changes in project efficiency, to measure the attitude of the operators and to foresee further developments also in the transposition of the project information model (PIM) into an asset information model (AIM).

\section{NEW ENEL HEADQUARTER IN ROME PROJECT}

The project concerns the renovation of the ENEL headquarters located in Rome in Viale Regina Margherita. The building consists of seven buildings connected to each other and spread over a total area of about 70,000 square meters, of which 55,000 square meters above ground. Following the renovation works, in addition to the traditional workstations, it will also have focus stations (for informal meetings, sharing, concentration, etc.) and various spaces and ancillary services (auditorium, meeting rooms, areas for informal meetings, company bar, kindergarten, gym, etc.). The redevelopment of the property will take place in autonomous functional lots; this aspect will require particular attention to the management of the workings and interferences, in order to guarantee the operational continuity of the portions of the complex from time to time not affected by the interventions carried out on the single functional lot.

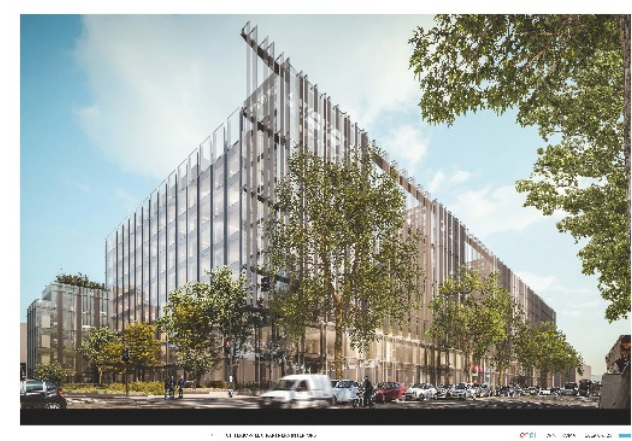

Figure 1: New ENEL Headquarters: Perspective view.

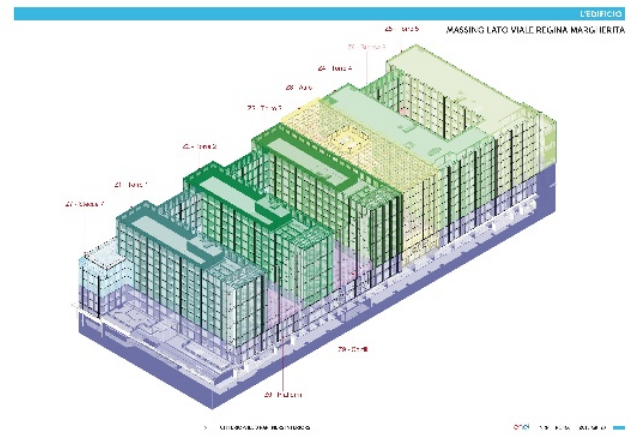

Figure 2: New ENEL Headquarters: Axonometric view.

\subsection{Organisational model}

ENEL has chosen to manage the construction of the new headquarters by entrusting the design and verification services to the architecture company Citterio Viel and Partners in 2018. Subsequently, in December 2019, the PMO and works management services were entrusted to an RTI formed by the companies Jacobs Italia S.p.A. and Artelia Italia S.p.A. In October 2020, the construction of the building to Colombo Costruzioni S.p.A. as main contractor. 


\subsection{ENEL Task Force and CITERA Group}

Enel (Italy's national entity for electricity) was founded in 1962 with the fusion of energy producers. With a solid bedrock of hydroelectric power as our starting point, the task was to power the country's rapid growth. The energy crisis of the following decade spurred the Company to explore alternative sources of power how renewable energy and ENEL pioneered a number of renewable energy plants around the world: hydroelectric plants, photovoltaic power station, and wind farm. Innovation and sustainability were become for ENEL two biggest drivers. Now that climate change has become increasingly evident, ENEL are fully aware of the impact the new energy era can have, with investments in digitalization, e-mobility, circular economy, and decarbonization.

Today ENEL sustainable approach is to create long-term shared value is guiding the energy transition, and ENEL aim to carry on finding new, innovative tools to contribute to positive growth, without ever losing sight of the future of Company. The digital revolution is one of the cornerstones of Enel's industrial strategy.

In May 2019, ENEL set up the Task Force Headquarters, in order to manage in a coordinated and integrated manner the execution of the renovation works of the Viale Regina Margherita complex, with the aim of:

- implement the tender project by directly managing the activities related to the execution of the works (site management, safety management, accounting, payments and testing);

- $\quad$ ensure compliance with the specifications, deadlines and costs budgeted, by monitoring the progress and managing all those involved, both internal and external to the company.

The structure was divided into four functional areas as listed below:

- Project health, safety and environment to ensure the application of policies, procedures and operating instructions on safety and the environment, supervise the management of safety and the environment on site, supervise, construction site with those inside and outside the building.

- Project design for the management of the integrated executive design and monitoring of the development of building information modeling, assessment of any non-conformities. In particular for the collection of data relating to the certification / homologation of the works, the use and maintenance manuals, all related to the as-built information model of the building, to be made available to the Services Italy unit for the management of the facilities management.

- Project execution for the execution of constructability analyzes of construction activities, verifying their feasibility with reference to the project requirements, coordination of construction site activities ensuring the achievement of objectives in terms of safety, environment, quality, time and costs.

- Project control for the definition, planning and monitoring of the activities necessary for the development of the project, implementation of the ordinary and extraordinary management of contracts and carrying out the associated risk analysis, ensuring the definition and execution of intercompany contracts, providing adequate transfer pricing criteria in collaboration with the other functions involved.

ENEL Task Force is supported for digital governance themes and by a Sapienza University of Rome CITERA Group. 


\subsection{Project's information requirements}

For this specific project, general strategic needs have been established, aimed at defining the operational specifications for the information management of the building process. In particular, the aim was to obtain:

Table 1: Main project information requirements.

\begin{tabular}{|l|l|}
\hline $\begin{array}{l}\text { Improvement of the level of knowledge of } \\
\text { the properties }\end{array}$ & Lower construction costs \\
\hline $\begin{array}{l}\text { Optimization of the design and subsequent } \\
\text { execution phases in compliance with } \\
\text { contractual deadlines }\end{array}$ & $\begin{array}{l}\text { Availability of reliable and useful } \\
\text { information for the management of the } \\
\text { works in the subsequent operational phase }\end{array}$ \\
\hline $\begin{array}{l}\text { Optimization of the bioclimatic balance of } \\
\text { the choices referred to the materials and } \\
\text { systems of materials present in it } \\
\text { environment }\end{array}$ & $\begin{array}{l}\text { Decision-making processes more } \\
\text { supported by timely, updated and reliable } \\
\text { information throughout the life cycle of the } \\
\text { building }\end{array}$ \\
\hline $\begin{array}{l}\text { Improvement of the health and safety of } \\
\text { workers employed on the construction site; }\end{array}$ & $\begin{array}{l}\text { Optimization of work management with } \\
\text { BIM methodology }\end{array}$ \\
\hline $\begin{array}{l}\text { Mitigation of the risks of variations in } \\
\text { progress }\end{array}$ & $\begin{array}{l}\text { Highlighting the breakdown of costs into } \\
\text { their primary components }\end{array}$ \\
\hline $\begin{array}{l}\text { Greater control of the execution times of } \\
\text { the works }\end{array}$ & $\begin{array}{l}\text { Collect and manage some data through the } \\
\text { model that can contribute to the economic/ } \\
\text { financial evaluation of the general } \\
\text { sustainability of the work }\end{array}$ \\
\hline Reduction of legal claims & $\begin{array}{l}\text { Implement a supervision of the } \\
\text { sustainability and the bioclimatic system } \\
\text { of the entire design and construction } \\
\text { process of the building }\end{array}$ \\
\hline
\end{tabular}

\section{CDE AS A PROJECT DIGITAL TWIN}

Collaboration between the participants involved in construction projects and in the management of real estate assets has a fundamental importance to ensure their efficient provision and management. Organizations are increasingly working in the context of new collaborative environments in order to achieve higher levels of quality and greater reuse of existing knowledge and experience. A core component of these collaborative environments is the ability to communicate, reuse and share data efficiently without data loss, contradiction or misrepresentation. This approach does not require any more work, as it has always been necessary to produce this information. However, true collaborative work requires mutual understanding and trust within the team and a deeper level of standardized process than previously experienced if information is to be produced and made available in a consistent and timely manner.

Information requirements must reach even the low levels of supply chains till the point where information can be produced more efficiently; furthermore, information must be collected as it moves up the supply chains. Currently, significant resources are devoted to correcting non-standard data, training new staff on approved data creation techniques, coordinating the efforts of subcontractor groups, and solving problems related to data reproduction. All of this is considered wasteful and can be reduced if the concepts and principles of the CDE are adopted jointly. A CDE is a system for managing data and 
information. The CDE is not just a web-based or cloud-based "data room". It includes the processes and rules necessary to ensure that people are working on or using the current version of a file or template, as well as to let them know what purposes they can use them for. These processes have been well defined and managed in the context of a paper filing system, however, with the adoption of new electronic technologies and the huge increase in data produced regarding a typical construction project, the need for good management it has been neglected and the old systems have not been replaced.

According to ISO 19650-1:2018, a CDE solution and workflow should be used for managing information during asset management and project delivery. During delivery phase, the CDE solution and workflow support the information management processes. At the end of the project, information containers required for asset management should be moved from PIM to AIM.

\subsection{Methodological approach to HQVRM CDE}

HQVRM CDE is a project aimed at experimenting, researching and developing the implementation methods of a crucial part of the BIM methodology: the structuring of the CDE for the renovation of the ENEL Headquarters. of Viale Regina Margherita (HQVRM). In particular, the research activities are aimed at defining a digital management framework for the organization of the construction site, and is aimed at monitoring the construction processes, enabling a correct flow of information between the various subjects participating in the construction of the work. The research, currently underway and which is developed over a minimum period of 2 years, is therefore aimed at structuring a cloud computing solution, developed on ENEL corporate technologies capable of having the Digital Twin. Within the solution all accredited subjects can share the information produced, according to pre-established rules. HQVRM CDE project is planned as a work in progress in which, according to intermediate milestones, it is possible to monitor the progress of subsequent developments.

HQVRM CDE features is going to implement main digital twin features: the set of data and information in any way referable to the entities represented by the digital twin; the connection between the elements of the physical component with the corresponding virtual (cybernetic) part; the possibility of ubiquitous access to data and IT resources through the web, with the possibility of searching and analyzing information (big data, machine learning, artificial intelligence).; the exchange of data and information between the virtual component (cybernetics) and the physical one, with the use of sensors and actuators.

All areas that have been designed within the "Digital Twin" have been structured through the use of standards, policies and company procedures.

Macro areas have been identified, within which the respective data have been collected. For example safety area is the area within which all the management of the data of companies, workers, vehicles, equipment, scaffolding and vehicles is carried out, through the collection of data aimed at authorizing entry to the construction site and the relative monitoring of their validity. The connection between the physical and digital elements are entrusted to actuators that allow the high level of interaction between the construction site and HQVRM CDE that allows a structured knowledge of the information relevant to the pursuit of the objectives of the ENEL Task Force. These include the actuators that allow controlled access to the site only by personnel actually authorized by the system on the basis of personal and documentary checks.

The main development activities of HQVRM CDE are summarized below: 
1. Analysis and evaluation of the client organization by verifying its strategic objectives, main functions, multi-year planning, regulatory and legislative constraints or related to particular technical/administrative acts. Structuring of the decision-making line, of roles and responsibilities and of the approval process and definition of the necessary needs and of the information flows in response to the achievement of the objectives.

2. Analysis and evaluation of the nature of the project and of the asset to be managed by defining the managerial, commercial and technical aspects of the production of information. The first two areas define the information standards and the production methods and procedures that must be implemented. The technical aspects define the pieces of information necessary to satisfy the information needs of the organization.

3. Analysis and evaluation of the methods of procurement of project and work services by identifying the information requirements useful for achieving specific strategic objectives in correspondence with each of the decision-making milestones in the various phases of the work.

4. Alignment of the management systems of the processes of the organization assessed in relation to the nature of the project and the asset and the procurement methods, through audit activities aimed at identifying information gaps and structuring information flows based on useful data and preferably structured in interoperable open formats necessary for the return of significant indicators.

5. Definition of contractual schemes that regulate the action of the parties in terms of methods and responsibilities, in the digital environment, in the supply chain, and depending on the phase, even structuring penalty metrics in the event of non-fulfillment.

6. Verification of enabling digital technologies, acquisition and implementation of the same, evaluating the nature of the work, the type of project, the competence of the staff and possibly structuring training plans consistent with the role held in the organization.

7. Surveillance, maintenance and continuous improvement of the data sharing platform and environment in the life cycle of the procedures and possible progressive development of artificial intelligence algorithms useful for improving the performance of the organization.

From what has been briefly explained, some first derivative considerations are therefore evident, which are summarized below:

A. HQVRM CDE is a cloud information resource available to the ENEL Task Force where the same manages the project in all phases, with rules previously shared and contracted through the information specifications/information management plan.

B. HQVRM CDE is the "place" for the execution of the contract, allowing the performance of the internal work group and/or external suppliers to be constantly monitored.

C. HQVRM CDE reflects the organizational structures of the ENEL Task Force and possibly enables better levels of it and on this it must be customized with scaled solutions and with costs previously estimated and calibrated on the objectives considered strategic.

\subsubsection{Development principles and requirements}

Collaborative work based on container objects, is midway along the maturity development path from documentation and paper drawings to server-based work, in which data is saved in centralized databases and multiple parties work simultaneously on a single model. The introduction of the concept of "work based on objects and their containers" or "work based on files", as a first step, introduces enough variation to create an impact; furthermore, this process is sufficiently close to current practice to be able to be implemented without requiring 
a substantial modification of the legal and contractual framework. It is also a process designed to make the adoption of this working methodology realistic also by SMEs.

The term "collaborative work based on objects and containers" was adopted from international standard ISO 19650-1:2018. An "object and its container" can be a threedimensional model, a drawing, a document, a table or a calendar; it is also often referred to as a "file". A database that contains multiple structured data tables is also a container object. Such objects can be categorized into document container objects, graphic information container objects, and even non-graphic information container objects. The collaborative working methodology based on container objects basically means two things:

1. The principle that the author or generator of a given information, for example a model or a design, has the competence and is responsible for the content and quality applied.

2. Certain rules have been defined regarding information management processes in order to allow a safe and efficient exchange of data and information.

\subsubsection{Needs and goals}

The activity is carried out in accordance with the principles that characterize the requirements for information management contained in the ISO 19650 series and in accordance with IT UNI 11337, based on the fact that the proposing subject (ENEL), the principal appointed subject (general contractor) and the other organizations in charge (PMO and GC) work together in a collaborative way and that all parties must participate in the implementation of the ISO 19650 series specific standards. The key requirements of HQVRM CDE are:

- Accessibility, according to pre-established rules, by all the actors involved in the process; Traceability and succession history of the revisions made to the data contained; Support for a wide range of data types and formats and their processing; High query flows and ease of access, recovery and extrapolation of data (open data exchange protocols); Conservation and updating over time; Confidentiality and security guarantee;

The objectives and advantages of HQVRM CDE are:

- Automation of information coordination between interested parties; Transparency of information also in terms of authorship and temporal availability of information; Automated management of revisions and data updates; Reduction of data redundancy; Reduction of risks associated with data duplication; Communication between interested parties through reference forms and interfaces (requests for information, requests, correspondence, etc.).

The solution was implemented using different technologies, in order to allow the development of an aggregate information model. The activity is monitored quarterly and, at the end of each quarter, an analysis phase is carried out by HQVRM CDE, aimed at assessing the results and results of the period relating to the quarter itself, validating the contents and possibly integrating the objectives.

\subsubsection{Main activities}

The activities are developed on the basis of ENEL's needs and the related input data provided and are carried out by the HQVRM CDE team, through the following main tasks:

1. Analysis of the ENEL information needs with reference to the objectives to be pursued, the contractual constraints and other corporate policy tools (organization, project, property);

a. Identification of the organization's information needs 
i. Data driven decision support for the ENEL Task Force;

ii. Structured knowledge of the progress of the work;

iii. Streaming monitoring;

iv. KPI performance measurement;

v. Reliable corporate and institutional disclosure and communication.

2. Identification of the information needs of the project

a. Supervise the execution of the project through checks (design reviews) carried out directly in the data sharing environment, or through reports extracted directly from the aforementioned environment or specific software that will be indicated by the Service Contractors according to the following paragraphs;

b. Simplify the assessments and estimates that ENEL will have to make, giving maximum transparency and control over the works to be carried out and the final results to be obtained;

c. Carry out simulations of the construction sequences on the model, aimed at validating the program, according to the availability of materials and the interference of the individual assembly activities;

d. Favor the economic control of the investment during construction and subsequent management, with traceability of materials coordinated with the execution phases of the works and subsequent phases;

e. Allow the analysis of the feasibility of the construction of the work, crossing the dates of availability of the materials on site, with the expected dates of assembly of the systems, collecting, in an organized form, all the relative certification documentation to be produced in accordance with the law and certifications subject to intervention (LEED, WELL, etc.);

f. Track the progress of progress during the construction phase, in digital and visual form;

g. Provide a basis that includes the minimum data and information necessary to ensure the correct setting and management of the subsequent management phases of the work;

h. Prepare, at the same time as the work is completed, an "IT" tool, which can also be used remotely, which allows the work to be managed during its useful life (such as, for example, operation, monitoring, maintenance, maintenance of necessary certifications).

3. Analysis of the tender documentation elaborated by ENEL and of the offers and information management proposals, elaborated by the RTI and GC;

4. Support for the definition of the initial contractual information management plan (ENEL/RTI/GC) and subsequent editions;

5. Structuring of HQVRM CDE according to ENEL proprietary rules and customized according to the company's own needs and procedures, developed on Microsoft technologies (mainly Sharepoint ${ }^{\circledR}$, Teams ${ }^{\circledR}$, PowerBI ${ }^{\circledR}$ ) and corresponding to the requirements of current main standards with particular reference to ISO 19650:2018 and UNI 11337:2017 implementation of HQVRM CDE, on the HQVRM redevelopment pilot project, by structuring sites, information sheets, metadata, taxonomies, authorization levels, etc.;

6. Continuous measurement of the efficiency and effectiveness of the rules established in order to gradually improve the process;

7. Progressive alignment of the contract documentation (information management plan) and simultaneous processing of what has been validated at the level of corporate strategic documentation (OIB-OIR-AIR-PIR). 
HQVRM CDE Team conducted sessions dedicated to the digital management of the project mainly attributable to the definition of the methods of management and coordination of the project processes and information flows, as well as the identification of the main information modeling rules. Over time, the aforementioned activities have also involved PMO and GC (with its subcontractors and third party contractors) and have been carried out by individual professionals or specific groups of professionals, The information processes of digitization have been managed, defining and managing general rules of the organization, research and development, training, resource management (human and instrumental), contracts, relations with mandatory and voluntary standardization systems, relations with higher bodies.

CDE management main functions needs:

1. Management and maintenance of the CDE and its use, the data contained therein, the databases connected to it and information applications in general, relations with higher bodies and information management;

2. Care and management within the individual orders, in the specifically digital information field of: declination of the general rules; information coordination internal and external to the organization; optimization of the use of resources (human instruments, etc.); progress of activities; relations with higher bodies.

A consistent information process must be guaranteed during all stages and phases of the process, taking care of the integrity of the data.

A solution and workflow of the CDE environment will be structured for the management of information during the management of the design, construction, preparation for management and delivery of the property itself to management.

At the end of the management of the building renovation project, the $\mathrm{CDE}$ will be prepared for the transfer from the job order information model (PIM) to the property management information model (AIM). The remaining job order information containers that will not be used for the management of the building will be stored in the CDE set up for the job itself. For the management of the $\mathrm{CDE}$, metadata will be structured for the various encodings.

\subsubsection{Reference standards and regulations}

Information management framework, including BIM, compliant with the following main regulations:

- UNI EN ISO 19650:2018 (Organization and digitization of information about buildings and civil engineering works, including building information modelling (BIM) Information management using building information modelling);

- UNI 11337:2017 (Building and civil engineering works - Digital management of the informative processes);

- $\quad$ Ministerial Decree MIT 560/2017;

- ISO 27001(Information technology - Security techniques - Information security management systems - Requirements);

- ENEL standards and regulations.

The goals of the CITERA Team concern the analysis of the needs framework of the proposing part of the project, the definition of KPIs, the modeling, implementation and management of digital information processes, defining and managing general rules of the organization, research and development, support training, management of resources (human and instrumental), support for contracts, relations with mandatory and voluntary standardization systems, relations with higher bodies. 
The management function of the ACDat includes:

- management and maintenance of the ACDat and its use, the data contained therein, the databases connected to it and information applications in general, relations with higher bodies and information management;

- care and management within the individual project, in the specifically digital information field, of: declination of the general rules;

- information coordination internal and external to the organization; optimization of the use of resources (human instrumental, etc.);

- $\quad$ progress of activities; relations with higher bodies.

Team CITERA also guarantees an information process during all stages and phases of the process, taking care of the integrity of the data. At the end of the management of the order, the ACDat is also prepared, if necessary, for the transfer from the information model of the order (PIM) to the information model of the management of the property itself (AIM) according to methods that will be communicated by ENEL. The remaining job order information containers that will not be used for the management of the building will be stored in the ACDat prepared for the job itself.

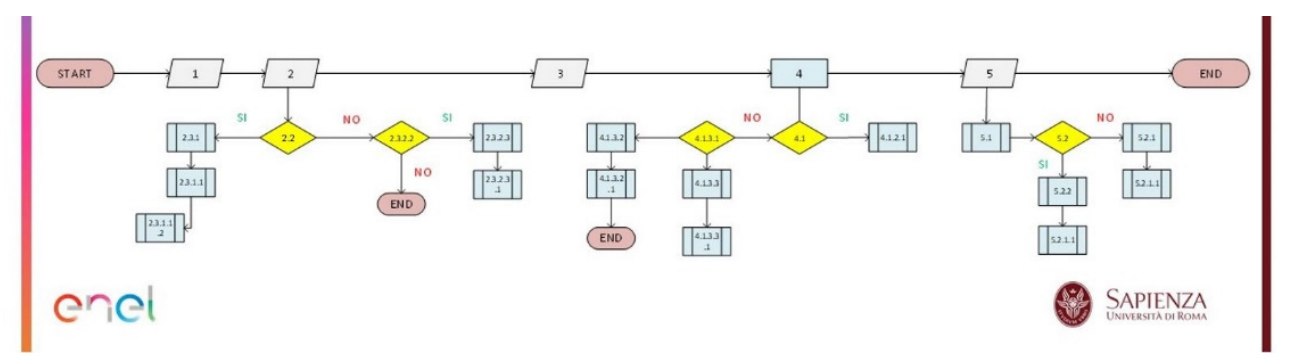

Figure 3: Workflow security.

\subsubsection{HQVRM CDE uses definition}

HQVRM CDE is intended as the set of tools and workflows used for the organization, management and sharing of data relating to the work. This set may vary over time in line with the evolution of the implementation process first and then management and the configuration of the subjects involved considering specific objectives and uses identified for HQVRM CDE.

HQVRM CDE is therefore structured according to the aggregation of multiple technological solutions each governed by internal workflows and related to each other through external workflows and is configured as $\mathrm{P}-\mathrm{CDE}$ project CDE in the management phase of the redevelopment project able to pass through in an A-CDE asset CDE under asset management. The analysis of the information needs of the ENEL Task Force made it possible to identify the main uses of HQVRM CDE:

1. Field and management tracking. Intended as the process in which a digital resource is used during the construction, and commissioning of a building to manage and monitor activities, report on quality, safety, construction documents etc. The goal is to ensure compliance with contract documents, compliance with safety regulations, and with the customer's project requirements;

2. Design repository and versioning; 
3. Design review, with issue resolution and request for information management;

4. 4D management;

5. 5D Management.

\subsection{Digital ecosystem}

The HQVRM - Digital Twin is based on a CDE of the organizational model and from the point of view of technologies is enabled by cloud computing, artificial intelligence, machine learning, big data and BIM. HQVRM-CDE represents the connective of the digital ecosystem in which information models are organized depending on the need and the objectives to be pursued in particular for the temporal, economic, safety and sustainability aspects.

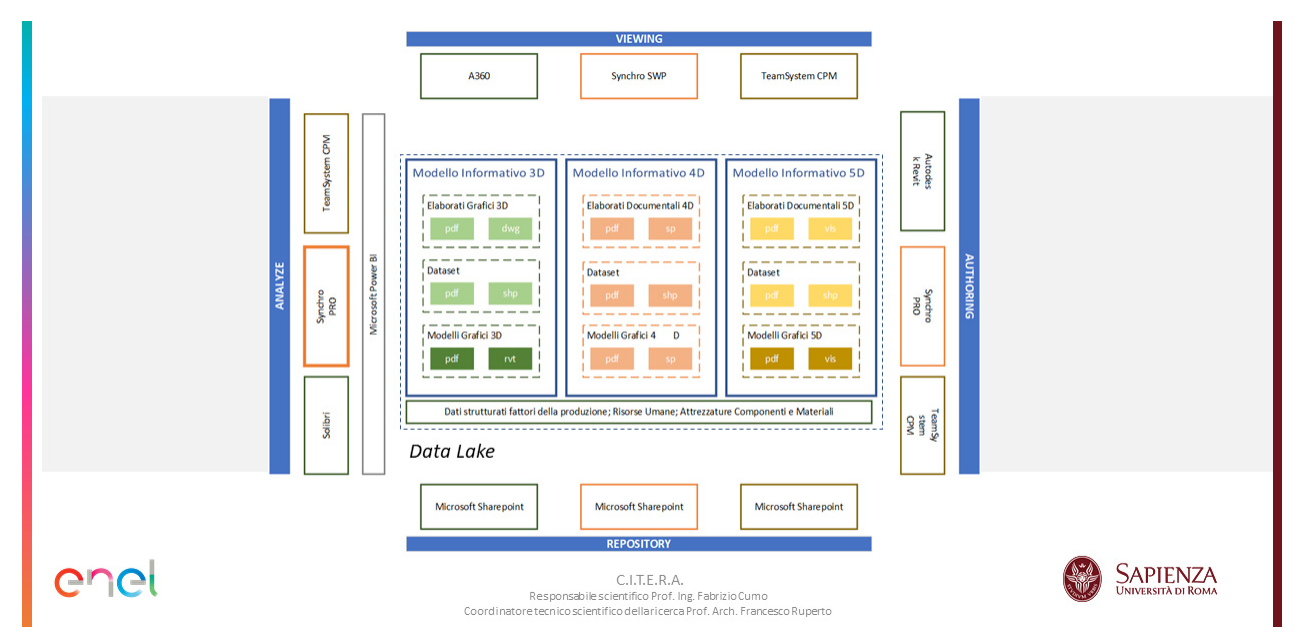

Figure 4: Environment structure.

\subsubsection{Content management system (CMS)}

Microsoft SharePoint ${ }^{\circledR}$ is a content management system (CMS) software platform developed by Microsoft, that is a program that, running on the server side, allows the creation and distribution of particular websites mainly for corporate use (intranet), but which can also be distributed on the net and therefore also be used as normal websites. The purpose of the software is to share information and/or documents in different ways. You can create lists, document repositories, calendars synchronized with Outlook ${ }^{\circledR}$ and more. SharePoint ${ }^{\circledR}$ is fully integrated with the Microsoft $365^{\circledR}$ package and the Power Platform and offers solutions such as document "versioning". Authentication is done by entering a username and password at login. This procedure is facilitated by single sign on, which in the context of Microsoft technologies is often inserted when turning on your PC. The system will therefore take care of automatically authenticating the user in the sites where he has access credentials. SharePoint ${ }^{\circledR}$ manages a system of permissions for its elements (site collection, site, list/ repository, page or folder/item). It is possible to associate a permission to each element, discriminating against any object mentioned above. This allows you to create particular websites in which, depending on the level of authorization a user has, it is allowed to see or not see certain elements by specifying the type of access (whether read-only or contributing). 
3.2.2 App development and workflow automation

Power Apps is a suite of apps, services, connectors and data platform that offers a rapid development environment for building custom apps for business needs. With Power Apps, you can quickly build custom business apps that connect to business data stored either in the underlying data platform (Microsoft Dataverse) or across multiple online and on-premises data sources (SharePoint ${ }^{\circledR}$, Microsoft $365^{\circledR}$, Dynamics $365^{\circledR}$, SQL Server ${ }^{\circledR}$, etc.). Microsoft Power Automate is the tool used for the automation of information flows.

\subsubsection{Business Intelligence}

The Business Intelligence tool adopted is Microsoft Power BI ${ }^{\circledR}$. PowerBI ${ }^{\circledR}$ is a collection of software services, apps, and connectors that work together to transform unrelated data sources into a coherent, visually engaging, and interactive set of information. The data can be structured in an Excel ${ }^{\circledR}$ spreadsheet or a collection of on-premises cloud-based or hybrid data warehouses. Power $\mathrm{BI}^{\circledR}$ allows to easily connect to data sources, view and discover important information, and share it with as many or as many users as you need.

\subsubsection{BIM authoring platform}

Autodesk Revit ${ }^{\circledR}$ is a CAD and BIM program for Windows operating systems, created by Revit Technologies Inc. and bought in 2002 by AutodesK, which allows design with elements of parametric modeling and drawing.

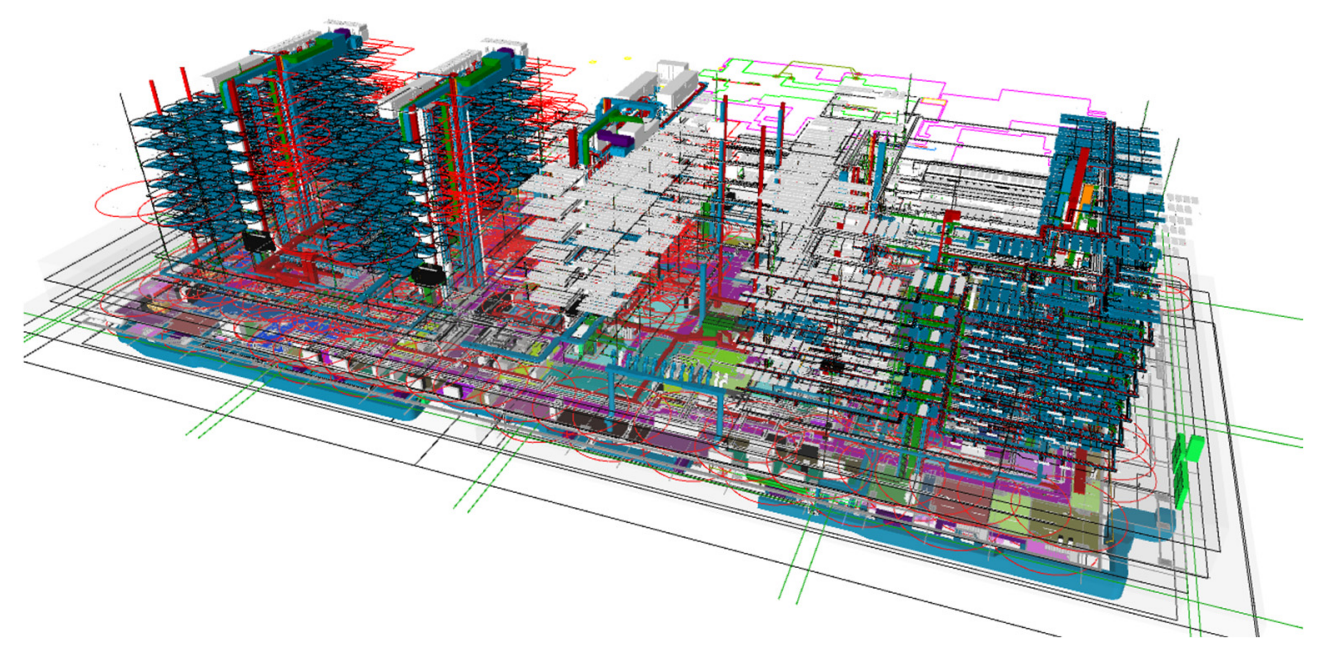

Figure 5: Axonometric view.

\subsubsection{D environment}

SYNCHRO is a complete portfolio of integrated software and services for digital construction management that allows project management based on 4D simulations, improving the use of data to optimize decision-making, resource monitoring and critical processes.

\subsubsection{D environment}

In order to ensure correct accounting of the works, the following requirements have been defined to be guaranteed: 
1. Connect the cost coding system, and the WBS by means of shared parameters relating to the WBS COMPUTO items, associated with each element/category within the model;

2. Specify the rules that generate the surveys, especially for those that are not a direct reading of the parameters of the elements of the model but a re-elaboration carried out on the basis of further calculation conventions;

3. Identify the nature and type of price lists/items of reference;

4. Method of extracting and linking data between price lists and model objects.

To pursue the aforementioned objectives, a software dedicated to the management of construction site costs (field BIM) has been identified in order to ensure the verification of the times and costs of execution analysis in progress relating to the progress and progress of the construction site, traceability of materials, etc.

The software identified for the management of the above is team system construction project management, which allows you to record the progress of the work. The correspondence of these advances with the virtual BIM model allows us to have even the visual rendering of the actual work progress of the work which can also be associated with any detailed analysis of the data allowed by the business intelligence functions made available by $\mathrm{CPM}^{\circledR}$.

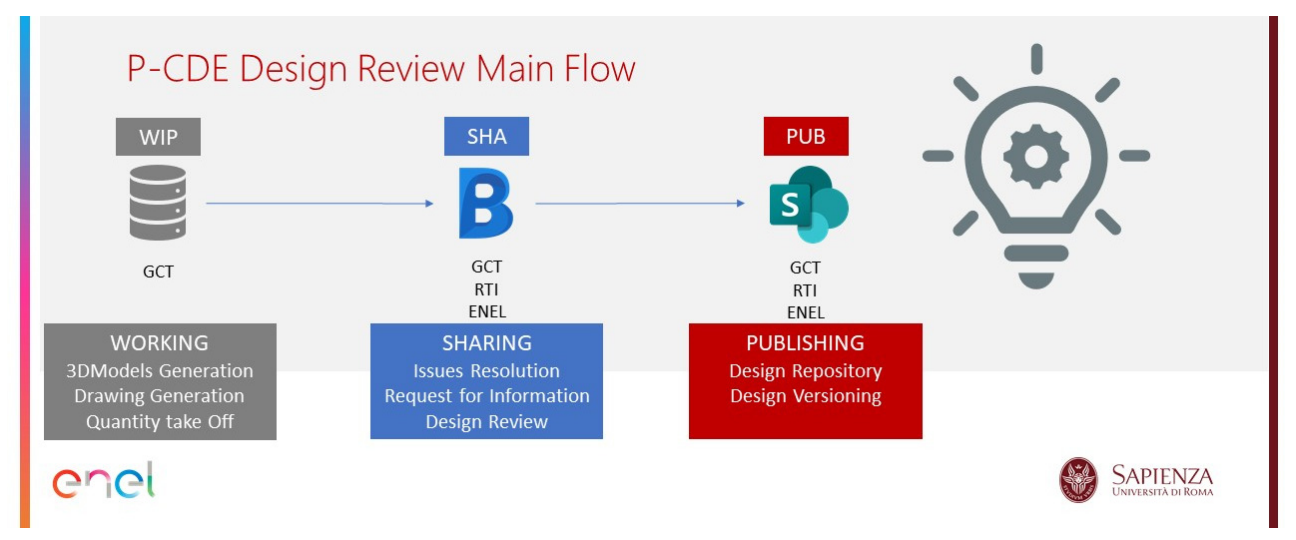

Figure 6: Project management workflow.

\section{CONCLUSIONS}

The information needs of the ENEL Task Force are aimed at monitoring the construction processes of the new headquarters, providing for the active collaboration of all the parties involved. To this end, the information flows concerning the project take place within a data sharing environment, in which the digital management of information processes takes place, made explicit through a process of correlation and optimization of digitized information flows and the decision-making processes that they concern every single activity. The objective of increasing the efficiency and effectiveness of the ENEL Task Force's monitoring action is pursued by establishing a framework of digital processes and technologies capable of enabling better levels of knowledge and control of each individual work phase in the main areas of safety and environment. A first evidence measured in carrying out the project, however, concerns the inevitable paradigm change required of all stakeholders; a transition that must gradually recognize its action which is less and less founded on documentary obligations and increasingly oriented towards managing and monitoring the construction site 
on data articulated in information containers. This digital transformation, on the one hand, therefore, allows an optimization of the Client's resources, on the other, imposes a general strategy aimed at increasing the reliability and availability of data on the basis of rules previously shared within the organization and contracted, also with collaborative approaches. in relations with suppliers.

In conclusion, whereas the main development activities of HQVRM CDE: (analysis and evaluation of the client organization, Analysis and evaluation of the nature of the project and of the asset to be managed, Analysis and evaluation of the methods of procurement of project and work services, Alignment of the management systems of the processes of the organization, definition of contractual schemes, verification, acquisition and implementation of enabling digital technologies and the surveillance, maintenance and continuous improvement of the data sharing) and his derivative considerations that we have previously discussed we can say HQVRM CDE constitutes a strategic asset of the organization capable of returning value in terms of efficiency, effectiveness and cost-effectiveness, to a greater extent depending on the specificity of the solution adopted and the medium / long-term vision capable of putting the governance apparatus of the project, recognizing its value also in terms of environmental sustainability (supporting the optimization of resources and reducing waste), economic (mitigating the risk of lengthening times and budget overruns), social (being able to enable higher levels of site safety), and ethics (favoring greater transparency and reducing moral hazard risk).

\section{ACKNOWLEDGEMENTS}

The views and opinions of the authors expressed in this paper do not necessarily reflect those of the ENEL S.p.A., or other collaborators, and responsibility for any errors or omissions rests solely with the authors. This research did not receive any specific grant from funding agencies in the public, commercial, or not-for-profit sectors. Authors are grateful to ENEL S.p.A. for making the case studies data available.

\section{REFERENCES}

[1] El Saddik, Digital twins: The convergence of multimedia technologies. IEEE MultiMedia, 25(2), pp. 87-92, 2018. DOI: 10.1109/MMUL.2018.023121167.

[2] Chhetri, M.B., Krishnaswamy, S. \& Loke, S.W., smart virtual counterparts for learning communities. Web Information Systems - WISE 2004 Workshops, Lecture Notes in Computer Science, 3307, pp. 125-134, 2004. DOI: 10.1007/978-3-540-30481-4_12.

[3] Bacchiega, G., Creating an embedded digital twin: Monitor, understand and predict device health failure (PDF). Inn4mech - Mechatronics and Industry 4.0 Conference Presentation, 2018. 